\title{
The Future of the Bamiyan Buddha Statues - Evolving Conservation Ethics and Principles concerning Intentionally Destructed Cultural Heritage
}

\author{
Masanori Nagaoka
}

The property (...) symbolises the strong hope of the Afghan and Bamiyan people that peace will be constructed in the minds of the citizens of this ravaged country, to enable the Afghan people to restore their lives and cultural heritage.

(Excerpt of the nomination dossier from the Government of Afghanistan's submission to the World Heritage Centre for the inscription of the Bamiyan site on the World Heritage List. http://whc.unesco.org/en/list/208/documents/ p. 5)

\begin{abstract}
Given the emerging dispute about the complexly intertwined issues of heritage reconstruction, conservation ethics and principles for intentionally destroyed cultural heritage has recently become one of the major topics for discussion within heritage studies; there is currently a move to refine theory and practice of heritage reconstruction, in light of intellectual and social developments, which recognize the importance of human rights and interlinkages between evolving disciplines of academia and policy. Whilst studying the case of the demolished Bamiyan Buddha statues and niches with the condition that most surface of the original fragments of the Buddha statues were lost, this volume attempts to provide a reference point for conservation practitioners and policy makers around the world as they consider how to respond to ongoing acts of destruction of cultural heritage properties. To reach this aim, this chapter first introduces how the issue of reconstruction of the Bamiyan Buddha statues arose and addressed. It then clarifies a
\end{abstract}

Published jointly by the United Nations Educational, Scientific and Cultural Organization (UNESCO), 7, place de Fontenoy, 75007 Paris, France, and Springer Nature Switzerland AG, Gewerbestrasse 1, 6330 Cham, Switzerland.

\footnotetext{
M. Nagaoka $(\triangle)$

UNESCO Office in Phnom Penh, Cambodia

e-mail: m.nagaoka@unesco.org
} 
scientific debate of the evolving thinking on heritage reconstruction issues pertaining to 'authenticity' and an impact to the Outstanding Universal Value of the World Heritage system, with the practical realities of implementing such decisions in a post-conflict setting.

Keywords Bamiyan $\cdot$ Buddha statues $\cdot$ World Heritage $\cdot$ Authenticity $\cdot$ Heritage reconstruction · Deliberate destruction · Iconoclasm · Peace building · Human rights

\section{Introduction: Debate on Heritage Reconstruction}

Acts such as iconoclasm and biblioclasm have a long history in the world, whether committed during wartime, revolutions or times of repression, but the early twentyfirst century has seen a new wave of deliberate destruction often publicly broadcast by the perpetrators. Recent prominent examples include the destruction of 16 tombs in Timbuktu, Mali, and damage to several World Heritage Sites in Syria, including the ancient classical city of Palmyra and the Grand Mosque in Aleppo. The international community has responded to these acts of violence and destruction with vigour. Setting a new precedent, the event of Timbuktu led to the first trial case for war crimes at the International Criminal Court in Hague in 2017 (United Nations 2017). Yet punitive measures are often inadequate to prevent attacks on cultural heritage, and historical sites will continue to fall victim to acts of destruction.

Reconstruction of cultural heritage due to acts of deliberate destruction has been recently addressed, not merely from the point of a material conservation philosophy but within the context of holistic strategies for the protection of human rights and promotion of peace building; The destruction of cultural properties is not just a loss for humanity, but it also deprives local populations of their identity, beliefs, history, integrity, memories and dignity (United Nations 2016). In contrast to earlier guidance that aimed to discourage reconstruction of historic places, recent World Heritage Committee decisions have explored new guidance on reconstruction of cultural properties that have been intentionally destroyed and obliterated.

In 2005, the World Heritage Committee made a review towards supporting reconstructions when it considered the Old Bridge Area of the Old City of Mostar in Bosnia-Herzegovina, which was destroyed after the breakup of former Yugoslavia (UNESCO 2005). Despite the fact that much new material was used, the ICOMOS report (ICOMOS 2005) clarified that the reconstructed bridge maintained an intrinsic sense of 'truthfulness', even though in strictly physical terms, a considerable portion consists of new material. The motivation for this change in position is the World Heritage Committee's desire to help recover lost identities for the concerned community and to take a stance against acts of aggression, 'underlining the unlimited efforts of human solidarity for peace and powerful co-operation in the face of overwhelming catastrophes' (UNESCO 2005, 141). 
Reconstruction of cultural properties is judiciously outlined in the Operational Guidelines of the Convention Concerning the Protection of the World Cultural and Natural Heritage (World Heritage Convention), which (UNESCO 2018b, 27) states ' $\ldots$ reconstruction of archaeological remains or historic buildings or districts is justifiable only in exceptional circumstances. Reconstruction is acceptable only on the basis of complete and detailed documentation and to no extent on conjecture'. Given the current move towards heritage reconstruction in post-war/post-conflict contexts, more detailed guidance is required with a view to reflecting the multifaceted challenges that heritage reconstruction brings, in its social and economic contexts, as a process that should be considered within the framework of the values, 'Outstanding Universal Value' (OUV) of the World Heritage properties (UNESCO 2018a).

Further exploration of reconstruction should be made with a high degree of consultation with impacted communities who have particular connections with heritage and suffered from its loss, in order to understand the meaning of heritage for them, incorporate the multiplicity of interpretations of heritage and determine whether or not they wish to rebuild, reconstruct and re-establish such heritage properties. And if there is community consensus for reconstruction, a number of additional inquiries arise, such as "How it will be done?"; "Who will decide?"; and "What it should be done for?". Moreover when it comes to the inscribed World Heritage properties, how can reconstructed heritage using new materials be considered to retain authenticity? Reconstruction of cultural heritage requires not only in-depth discussion in a multidisciplinary approach by experts and academia but also a long-term vision for the preservation and interpretation of such reconstructed heritage, which duly requires the involvement of community who are suffered from damaged and/or lost heritage.

Given the emerging dispute about the complexly intertwined issues of heritage reconstruction, conservation ethics and principles for intentionally destroyed cultural heritage has recently become one of the major topics for discussion within heritage studies, resulting in numerous publications and dedicated academic journals; there is currently a move to refine theory and practice of heritage reconstruction, in light of intellectual and social developments, which recognize the importance of human rights and interlinkages between evolving disciplines of academia and policy. Hence, the preparation of a clear heritage reconstruction principles, comprehensive conservation strategies and guidelines is required to respond to an ongoing debate and community's request. Whilst studying the case of the demolished Bamiyan Buddha statues and niches with the condition that most surface of the original fragments of the Buddha statues were lost (ICOMOS 2014), this publication attempts to provide a reference point for conservation practitioners and policy makers around the world as they consider how to respond to ongoing acts of destruction of cultural heritage properties. 


\section{Protecting the Bamiyan World Heritage Site}

In March 2001, two Buddha statues located in the Bamiyan Valley, believed to date back, respectively, to the mid-sixth and the early seventh century AD, were destroyed (Transitional Islamic State of Afghanistan 2003). This destruction led to the mobilization of the international community to strongly condemn this act and initiated the adaptation of the 2003 Declaration concerning the Intentional Destruction of Cultural Heritage. ${ }^{1}$

The unique Buddhist monuments, along with multiple monumental sites in the Bamiyan Valley from different Islamic and pre-Islamic periods, attest to the successive interactions between societies living in this region by those who passed through along the Silk Roads. The OUV of these historical monuments and cultural landscapes was recognized by the World Heritage Committee in 2003, the year in which the site was inscribed on the World Heritage List as a case of emergency nomination. At that time, the Bamiyan Valley was simultaneously placed on the List of World Heritage in Danger due to ongoing challenges to conservation status of the nominated cultural properties and overall management of the site.

At its 31st session in New Zealand in 2007, the World Heritage Committee (UNESCO 2007) defined a series of corrective measures to achieve a 'Desired State of Conservation', which would enable the removal of Bamiyan from this Danger List. These included:

1. Acceptable levels of site security

2. Addressing issues concerning structural stability of the two standing Giant Buddha niches

3. An adequate state of conservation of archaeological remains and mural paintings

4. Completing and implementing an effective Management and Cultural Master Plan.

Over the past decades, UNESCO and the Government of Afghanistan have worked in partnership to undertake a series of actions to protect the various values in Bamiyan with generous contributions from the Governments of Germany, Italy, Japan, Korea and Switzerland, as well as the World Bank through the Afghan Government. In the case of a financial support from the Government of Japan, UNESCO received more than USD ten million to ensure the preservation of the values of cultural properties in Bamiyan. The Phases I to IV project from 2003 to 2015 focused on emergency interventions to conserve and rehabilitate the fragile archaeological and geological context of the site, a massive task of stabilizing the Buddha niches and preventing their collapse, archaeological survey, mural painting conservation and heritage zoning management planning for the preservation and promotion of various World Heritage properties in Bamiyan. Commencing from 2015, Phase V of the project focused on the defined specific benchmarks to lay the foundations to remove the site from the List of Heritage in Danger in the near future.

\footnotetext{
${ }^{1}$ https://unesdoc.unesco.org/ark:/48223/pf0000133874
} 
Within the following Japan-funded project beginning from 2020, the primary actions are identified to meet the above-mentioned set benchmarks.

\section{Revitalization of the Bamiyan Buddha Statues}

Since their destruction by the Taliban in March 2001, the former Buddha statues in Bamiyan have been the focus of concerted conservation efforts to stabilize the niches and surrounding cliffs. After the completion of the works of stabilization and conservation at the Eastern Buddha niche rear face and surrounding staircases in 2011, a technical scaffolding rig for the imminent commencement of similar works in the Western Buddha niche was added in 2013 (UNESCO 2013). During the preservation initiative of the damaged Buddha niches, the international community, including UNESCO, has been continuously lobbied by the Afghan Government for advice and guidance regarding the concept of wholly or partially reconstructing both or either of the Buddha statues.

The ninth Bamiyan Working Group Meeting at UNESCO Headquarters in March 2011 (UNESCO 2011) recommended that the larger Western Buddha niche be consolidated and left empty as a testimony to the tragic act of destruction and that a feasibility study be undertaken to determine whether or not a partial reassembling of fragments of the Eastern Buddha statue could be a future option in the coming years.

In August 2013 limited restoration and conservation works began at the floor level inside of the Eastern Buddha niche as an additional element of a project of ICOMOS Germany to install a protective roof and sustaining pillars (UNESCO 2013). However the project was temporarily put on hold in September 2013 after ICOMOS Germany installed foot-shaped structures within the Eastern niche itself. Following the recommendation at the twelfth Bamiyan Expert Working Group Meeting from 10 to 11 December 2013 in Orvieto, Italy, a mission of two ICOMOS International experts was sent to Bamiyan from 26 May to 2 June 2014, in order to evaluate the appropriateness of the intervention made by ICOMOS Germany at the site. The ICOMOS International Advisory Mission report (ICOMOS 2014, 28) recommends that:

a well-researched study is commissioned on the feasibility and options for the reconstruction of the Eastern Buddha as a basis for a well-informed debate on this issue, involving all the many stakeholders at local, national and international levels.

In order to meet the Afghan Government's request and the recommendation of the 2014 ICOMOS International mission, UNESCO organized a technical meeting at the World Heritage Centre in Paris, July 2014. During this meeting, participants of UNESCO, Afghan officials and concerned international experts (UNESCO 2014) agreed to explore a scientific study by convening an international technical meeting on the issues and practicalities associated with Buddha statue reconstruction. 
At the 12th Bamiyan Expert Working Group in 2013, the former Acting Minister of Information and Culture, H.E. Mr. Nabi Farahi (UNESCO 2013), requested at least partial reconstruction of one of the Buddha statues. At the 13th Bamiyan Working Group Meeting in Munich in December 2016, the Governor of Bamiyan (UNESCO 2016a) reiterated the Government's and local community's desire to reconstruct at least one of the Buddha statues. Because the consolidation work on the Eastern Buddha niche has been completed in 2011, it was once again agreed during the meeting in Munich in 2016 that an international technical meeting would be convened in the following year, in order to discuss the future treatment of the Eastern Buddha niche (UNESCO 2016a). The 40th World Heritage Committee in 2016 (UNESCO 2016b) also acknowledged the Afghan authorities' wish to partially reconstruct at least one of the Buddha niches.

Responding to the request of the Government of Afghanistan and the decisions of the World Heritage Committee at its 40th session concerning the deliberate destruction and reconstruction of cultural heritage in areas of conflict, in particular the Buddha statues in Bamiyan, UNESCO, together with the Government of Afghanistan and the Tokyo University of the Arts, with a financial support of the Government of Japan, organized an international technical meeting, entitled 'The Future of the Bamiyan Buddha Statues: Technical Considerations and Potential Effects on Authenticity and Outstanding Universal Value' in Tokyo, Japan from 27 to 30 September 2017. The aim of the meeting was to foster an exchange of research, experience and observations in order to clarify heritage conservation theory and practice of reconstruction of cultural properties and to examine a number of technical proposals presented by international experts in their fields, concerning the potential reconstruction of one or more of the Buddha statues at the Bamiyan World Heritage Property. Such a study will contribute to a better understanding of past approaches and current practice in order to provide guidance to meet the needs of the twenty-first century.

The secondary reason for holding the technical meeting was to discuss the positive role that the reconstruction of heritage can play in fostering nations' understanding of their history and identity, recognition of human rights, mutual respect among peoples and of the diversity and equal dignity of the world's cultures. It was of central significance to the technical meeting that the concerned government representatives, technical experts and donors recognize the importance of the role culture to contribute in the peacebuilding and development process specifically in conflict or post-conflict regions.

Prior to the organization of this meeting, the Government of Afghanistan and UNESCO invited applicants to submit proposals for either physical revitalization of the Eastern Buddha statue or its non-physical revitalization in the niche, in order to present the Government with a balanced range of options reflecting the diverse spectrum of opinions about revitalization. ${ }^{2}$ Several proposals were submitted and

\footnotetext{
${ }^{2}$ Physical revitalization implies rebuilding the Eastern Buddha statue, whereas non-physical revitalization implies measures to interpret the Eastern Buddha statue without any physical form of statue reconstruction.
} 
reviewed by the designated Scientific Committee members, prior to the meeting. Once the proposals met the conditions and criteria of the proposal application guidelines, four proposals were presented at the Tokyo meeting. In this regard, the Tokyo meeting in 2017 came at an important milestone which set concrete foundations for the Government of Afghanistan to decide how to proceed with the reconstruction (or not) of the Bamiyan Buddha statues.

Yet there is still an emerging issue of the impact to the OUV concerning heritage reconstruction of the Bamiyan Buddha statues. Considering that the Eastern Buddha niche, without a standing Buddha statue, was inscribed in the World Heritage List in 2003 as part of the 'Cultural Landscape and Archaeological Remains of the Bamiyan Valley', it was deemed a challenge to reconstruct it because any physical reconstruction of the Buddha statues shall give an impact to the originally inscribed status of the empty niche. Therefore the discussion should focus on not only a technical question of statue reconstruction but also conservation ethics and retention of authenticity as a World Heritage Site, which requires to comply with a range of policies set out by the Operational Guidelines of the World Heritage Convention.

\section{Varying a Concept of Heritage Authenticity}

There has been an emerging debate among international conservators and restorers as to the ethics and nature of heritage reconstruction, but the prevailing opinion amongst those who are in favour of restoring one of the statues at Bamiyan is an approach that utilizes the available original material for a partial restoration of the statues. This idea is in accordance with the discourse of conservation ethics and authenticity that has prevailed in the twentieth century. As seen in the Venice Charter, and any other international charters and treaties, reconstruction of heritage using non-original materials was not allowed because heritage authenticity was considered as a critical foundation of inheritance of a historic value of heritage. The Venice Charter for the Conservation and Restoration of Monuments and Sites (ICOMOS 1964) states that:

\footnotetext{
The process of restoration is a highly specialized operation. Its aim is to preserve and reveal the aesthetic and historic value of the monument and is based on respect for original material and authentic documents. It must stop at the point where conjecture begins, and in this case moreover any extra work which is indispensable must be distinct from the architectural composition and must bear a contemporary stamp. The restoration in any case must be preceded and followed by an archaeological and historical study of the monument... All reconstruction work should however be ruled out "a priori". Only anastylosis, that is to say, the reassembling of existing but dismembered parts can be permitted. The material used for integration should always be recognizable and its use should be the least that will ensure the conservation of a monument and the reinstatement of its form.
}

The ICOMOS Charter for the Protection and Management of the Archaeological Heritage (ICOMOS 1990) also clarifies that: 
Reconstructions serve two important functions: experimental research and interpretation. They should, however, be carried out with great caution, so as to avoid disturbing any surviving archaeological evidence, and they should take account of evidence from all sources in order to achieve authenticity. Where possible and appropriate, reconstructions should not be built immediately on the archaeological remains, and should be identifiable as such.

From the twenty-first century, the concept of cultural heritage and heritage authenticity has shifted away from a focus on monumental and physical heritage and now encompasses notions of living heritage, traditional knowledge, language, cultural diversity and performing arts (Daly 2012; Lloyd 2012; and etc.). Hence the principles of heritage underlying the Venice Charter and others have come under review. For instance, intangible culture has become one of the major topics for discussion within heritage studies. This builds on critiques of the material-centric view of heritage over heritage discourse and practice. Taylor (2004) argues that heritage in Asian contexts, for instance, differs from the European theoretical and practical understanding of heritage. Lloyd (2012) also stresses that heritage in Asian contexts often differs from the commonly perceived heritage forms of historic monuments and 'high culture'. Taylor (2004. p. 423) asserts that 'Asian cultures have a spiritual view of what is culturally valuable from the past; the past lives on in memory of people, of events and of places through time rather than concentrating on the material fabric which can change or be replaced'.

These ideas and concept of heritage are well introduced in the 1994 Nara Document on Authenticity, the 1998 China Principles, the 2002 Shanghai Charter, the 2004 Yamato Declaration, the 2005 Hoi An Protocols, the 2005 Xi' an Declaration and the 2007 Seoul Declaration. The Nara Document (ICOMOS 1994) first articulated an evolving approach and a distinctively Asian perspective on authenticity, recognizing that the ways and means of preserving the authenticity of cultural heritage are themselves culturally dependent. Paragraph 11 of the Nara Document (ICOMOS 1994, 3) states that 'All judgments about values attributed to cultural properties as well as the credibility of related information sources may differ from culture to culture, and even within the same culture'. It is thus not possible to base judgements of values and authenticity within fixed criteria. There are other declarations and charters articulating an evolving approach and a distinctively way of achieving authenticity in Asia, recognizing that the ways and means of preserving the authenticity of cultural heritage are culturally dependent:

\footnotetext{
The value of a heritage site derives from ... the site illustrates the material production, lifestyle, thought, customs and traditions or social practices of a particular historical period. Principles for the Conservation of Heritage Sites in China (ICOMOS 2002, 71) ... affirming the significance of creativity, adaptability and the distinctiveness of peoples, places and communities as the framework in which the voices, values, traditions, languages, oral history, folk life and so on are recognized and promoted in all ... heritage practices ...Shanghai Charter (ICOM 2002, 1)
}

The Hoi An Protocols declared in 2001, revised periodically and published in 2009, provides another example:

The immaterial dimension of authenticity (e.g. artistic expression, values, spirit, emotional impact, religious context, historical associations... and creative process) and sources of information about them are particularly important in regard to maintaining authenticity of 
cultural heritage in Asia. - Hoi An Protocols for Best Conservation Practice in Asia (UNESCO Bangkok 2009, 12)

These Protocols clarify that an 'Asian' understanding of heritage concept and value includes, 'for example, a continuous craft tradition handed down generation by generation, an unbroken oral tradition, a ritual of which the practice is in the hands of hereditary specialists' (Engelhardt 2012, 312). The Protocols state that 'Authentic cultural assets are passed through time and communities by un-interrupted transmission, evolving but retaining the essential qualities that make them authentic' (UNESCO Bangkok 2009, 13). Whilst this concept of heritage and its authenticity have been acknowledged globally, these are also included into the Operational Guidelines of the World Heritage Convention in 2005, recognizing the ways and means to preserve cultural heritage and different understandings of heritage that existed outside Europe.

Since the beginning of the twenty-first century, UNESCO has commenced reviewing the issues regarding maintaining authenticity of cultural heritage, especially in face of acts of deliberate destruction. Heritage authenticity and reconstruction are currently under an important transition because revitalization of heritage due to iconoclasm and deliberate acts of vandalism or conflicts should not be discussed only within the context of material conservation and restoration but also requires more holistic strategies for the protection of human rights and the promotion of peace. With the introduction of this new approach, the Warsaw Recommendation on Recovery and Reconstruction of Cultural Heritage in 2018 proposed a comprehensive set of principles to heritage reconstruction as a result of armed conflicts or natural disasters. The Recommendation (UNESCO 2018c, 2-3) states that:

\begin{abstract}
the overall goal is the recovery of the society. This aims at the consolidation of peace and security and at restoring or improving the economic, physical, social, cultural and environmental assets, systems and activities of an affected community or society, aligning with the principles of sustainable development and "build back better". An essential part of this process is the recovery of the places' heritage, which may include reconstruction. The term "reconstruction", in the World Heritage context, is understood as a technical process for the restitution of destroyed or severely damaged physical assets and infrastructure following an armed conflict or a disaster. It is important to stress, in this regard, that such reconstruction of physical assets must give due consideration to their associated intangible practices, beliefs and traditional knowledge which are essential for sustaining cultural values among local communities.
\end{abstract}

What should be achieved from heritage reconstruction? It should address not merely a physical restoration of damaged heritage but the recovery of the society needs. Whilst respecting heritage conservation principles, the recovery and reconstruction of World Heritage properties following armed conflict or disasters caused by natural hazards need to address 'the legitimate aspiration of concerned communities to overcome the trauma of conflicts, war and disasters by reconstructing as soon as possible their cities and villages - and particularly their affected cultural heritage - as a means to reaffirm their identity, restore their dignity and lay the conditions for a sustainable social and economic recovery' (UNESCO 2018c, 2). The Warsaw Recommendation (UNESCO 2018c, 2) also underlines that 'the recovery 
of the cultural heritage lost or damaged as a result of armed conflict offers unique opportunities, notably within the context of stabilization processes, to foster mutual recognition, promote dialogue and lay the ground for reconciliation among all components of society, particularly in areas characterized by a strong cultural diversity and/or hosting important numbers of refugees and/or internally displaced people, which will lead to new approaches to recovery and reconstruction in the future'.

\section{Intention of the Publication: Debate on the Reconstruction of the Bamiyan Buddha Statues}

There is currently a dearth of literature pertaining specifically to the ethics of heritage reconstruction in Afghanistan, with particular reference to the Buddha statues in Bamiyan. Introducing ideas of academics and heritage restoration experts concerning issues pertaining to 'authenticity', and an impact to the OUV at the site in light of potential reconstruction works at World Heritage Sites, this publication aims to provide a reference for heritage conservation practitioners and policy makers around the world as they consider how to respond to ongoing acts of destruction of cultural monuments.

After this introductory chapter, the publication explains in Part II an overall review of the emergency interventions at the Bamiyan World Heritage Property implemented from 2003 to 2020. Mounir Bouchenaki first introduces the significant historical account of the destruction of the Bamiyan Buddha statues. Bert Praxenthaler and Matthias Beckh outline the challenges and achievements of the preservation works of the Buddha niches and fragments. Yoko Taniguchi explains the conservation status and restoration efforts of the Bamiyan's Buddhist wall paintings and introduces historical findings of the adopted painting method. Michael Jansen and Georgios Toubekis clarify the nature and objectives of the Bamiyan Cultural Master Plan to protect the values of OUV of the cultural landscapes in the Bamiyan Valley.

Part III introduces academic research and experience of heritage conservation and practice of reconstruction of deliberately destructed cultural properties. Mechtild Rössler introduces recent decisions of the World Heritage Committee concerning the deliberate destruction of cultural heritage. Maamoun Abdulkarim explains the case of destruction and rehabilitation efforts of demolished Palmyra. Lassana Cisse clarifies ways of reconstruction of the destroyed mausoleums in Timbuktu, Mali, by introducing the reconstruction strategy in a community participatory approach. Michael Turner also argues how the destroyed Bamiyan Buddha statues should be treated, referring to the case study of reconstruction of Jewish synagogues after World War II.

Part IV attempts to clarify heritage conservation theory and practice of reconstruction of cultural properties. Cornelius Holtorf outlines that reconstructions and reinvented heritage can have a powerful role in society; therefore, the appropriate stakeholders should play an important role to decide for the benefit of specific future 
generations by identifying appropriate management strategy. Marie Louise Stig Sørensen discusses the classic heritage tensions and challenges that are linked to the proposed reconstruction of the Bamiyan Buddha statues. Through the case of the creation of the Ground Zero Memorial in New York following the attack of the World Trade Center buildings in New York City, Helaine Silverman explores how to fill the absence of the lost countries' icons from the points of the technical, social, emotional, national, local and economic interests.

Part $\mathrm{V}$ explores how to address the damaged Buddha statues and identify ways for their future treatment. Jukka Ilmari Jokilehto argues that a priority should be given to the urgent completion of consolidation and the continuation of safeguarding of the remains whilst strongly recommending not to propose any reconstruction or anastylosis in the niches because the present remains are the most efficient memorial to the 2001 destruction. Deborah Klimburg-Salter explores a new perspective of the evolution of Bamiyan colossal sculptures that assists in understanding the discrepancy between the Islamic sources, including the Afghan oral traditions, and the western sources. And from this interpretation, she concludes that the empty niches offer greater interpretive flexibility and potential to contribute to the peacebuilding process. Junko Okahashi attempts to identify the 'exceptional' and acceptable conditions to reconstruct the Bamiyan Buddha statues. James Janowski argues the meaning and the absence of the value in the emptiness of the Bamiyan niches and clarifies the relation between deliberately induced emptiness and inauthenticity on one hand and physical reconstruction and the reestablishment of authenticity on the other.

Part VI introduces technical intervention methods and proposals from Italy, Japan and Germany concerning the reconstruction of Bamiyan Buddha statues, in particular issues pertaining to 'authenticity' and an impact to the OUV at the site in light of potential reconstruction works at the Bamiyan World Heritage Site.

As an output of the Tokyo meeting in 2017, unanimously adopted conclusions by the meeting participants are introduced in the annex. And the Afghan authorities' decisions to the submitted technical concepts presented by international experts during the Tokyo meeting in 2017 are also introduced in the annex. After the Tokyo meeting, the Afghan authorities had organized a series of national Technical Working Committee meetings in 2018 that the Afghan Ministry of Information and Culture initiated throughout the year. The decisions of the national Technical Working Committee meetings include an action plan with a timeframe based on findings of opportunities and challenges concerning all four proposals presented at the Tokyo meeting.

The publication is intended to contribute to the available literature on heritage conservation ethics post-conflict and provide an important historical record of the possible reconstruction of the Bamiyan Buddha statues for future. This publication is also intended to create a well-documented precedent for potential decisions taken elsewhere in the world for cultural properties similarly impacted by acts of violence and destruction. Scientifically providing an account of different perspectives on heritage reconstruction ethics, the publication aims to offer a plethora of ideas and approaches concerning the deliberately damaged cultural heritage. 


\section{References}

Daly, P. (2012). Fighting modernity: Traditional Chinese martial arts and the transmission of intangible cultural heritage. In P. Daly \& T. Winter (Eds.), Routledge handbook of heritage in Asia (pp. 350-363). London: Routledge.

Engelhardt, R. (2012). The hoi an protocols for best conservation practice in Asia: Application to the safeguarding of Asian cultural landscapes. In K. Taylor \& J. L. Lennon (Eds.), Managing cultural landscapes (pp. 308-324). London: Routledge.

ICOM. (2002). Shanghai charter. Shanghai: ICOM.

ICOMOS. (1964). The Venice charter for the conservation and restoration of monuments and sites. Paris: ICOMOS.

ICOMOS. (1990). The charter for the protection and management of the archaeological heritage. Paris: ICOMOS.

ICOMOS. (1994). The Nara document on authenticity. Paris: ICOMOS.

ICOMOS. (2002). Principles for the conservation of heritage sites in China. Los Angeles: The Getty Conservation Institute.

ICOMOS. (2005). Mostar (Bosnia and Herzegovina) No 946 rev of ICOMOS Advisory Body Evaluation report. Paris: ICOMOS. Retrieved from https://whc.unesco.org/en/list/946/ documents/

ICOMOS. (2014). Report on the ICOMOS advisory mission to cultural landscape and archaeological remains of the Bamiyan Valley (208rev). 26th to 31 st May 2014. Paris: ICOMOS.

Lloyd, G. (2012). Legislating to safeguard Asia's intangible heritage. In P. Daly \& T. Winter (Eds.), Routledge handbook of heritage in Asia (pp. 139-152). London: Routledge.

Taylor, K. (2004). Cultural heritage management: A possible role for charters and principles in Asia. International Journal of Heritage Studies. London: Routledge.

Transitional Islamic State of Afghanistan. (2003). World heritage nomination: Cultural landscape and archaeological remains of the Bamiyan Valley for inscription on the World Heritage list and on the list of World Heritage in Danger. Kabul: Afghanistan.

UNESCO. (2005). Decisions of the 29th session of the World Heritage Committee. Presented at the Twenty-ninth Session of the World Heritage Committee in Durban, South Africa from 10 to 17 July 2005. Paris: Retrieved from http://whc.unesco.org/archive/2005/whc05-29com-22e.pdf

UNESCO. (2007). Decisions of the 31st session of the World Heritage Committee. Presented at the Thirty-first Session of the World Heritage Committee in Christchurch, New Zealand from 23 June to 2 July 2007. Paris: Retrieved from http://whc.unesco.org/archive/2007/whc0731 com-24e.pdf

UNESCO. (2011). Recommendations of the 9th expert working group meeting for the preservation of the safeguarding of the cultural landscape and archaeological remains of the Bamiyan Valley world heritage property. UNESCO Headquarters, Paris from 3 to 4 March 2011. Paris: UNESCO.

UNESCO. (2013). Recommendations of the 12th expert working group meeting for the preservation of the safeguarding of the cultural landscape and archaeological remains of the Bamiyan Valley World Heritage Property. Orvieto, Italy from 10 to 11 December 2013. Paris: UNESCO.

UNESCO. (2014). Minutes of the Bamiyan phase V preparation meeting. UNESCO Headquarters, Paris from 8 to 9 July 2014. Paris: UNESCO.

UNESCO. (2016a). Recommendations of the 13th expert working group meeting for the preservation of the safeguarding of the cultural landscape and archaeological remains of the Bamiyan Valley world heritage property. Munich, Germany from 1 to 3 December 2016. Paris: UNESCO.

UNESCO. (2016b). Report of the decisions adopted during the 40th session of the World Heritage Committee. Fortieth session of the World Heritage Committee in Istanbul, Turkey from 10 to 17 July 2016. Paris: UNESCO. Retrieved from http://whc.unesco.org/archive/2016/whc1640com-19-en.pdf

UNESCO. (2018a). Decisions adopted during the 42nd session of the World Heritage Committee. Presented at the Forty-second session of the World Heritage Committee in Manama, Bahrain 
from 24 June to 4 July 2018. Paris: UNESCO. Retrieved from http://whc.unesco.org/ archive/2018/whc18-42com-18-en.pdf

UNESCO. (2018b). Operational guidelines for the implementation of the world heritage convention. Paris: UNESCO.

UNESCO. (2018c). Warsaw recommendation on recovery and reconstruction of cultural heritage. Paris: UNESCO.

UNESCO Bangkok. (2009). Hoi an protocols: Professional guidelines for assuring and preserving the authenticity of heritage sites in the context of the cultures of Asia. Bangkok: UNESCO. http://www2.unesccobkk.org/elig/publications/242/HoiAnProtocol.pdf

United Nations. (2016). Report of the special Rapporteur in the field of cultural rights in UN General Assembly. New York: United Nations.

United Nations. (2017). President of international criminal court calls for greater cooperation in holding atrocity crime perpetrators accountable. Meeting coverage in the 72nd Session, 36th and 37th meetings at the General Assembly. New York: United Nations. Retrieved from https:// www.un.org/press/en/2017/ga11966.doc.htm

The opinions expressed in this chapter are those of the author(s) and do not necessarily reflect the views of the UNESCO, its Board of Directors, or the countries they represent.

Open Access This chapter is licensed under the terms of the Creative Commons AttributionShareAlike 3.0 IGO License (https://creativecommons.org/licenses/by-sa/3.0/igo/), which permits use, sharing, adaptation, distribution, and reproduction in any medium or format, as long as you give appropriate credit to UNESCO, provide a link to the Creative Commons licence and indicate if changes were made. If you remix, transform, or build upon this chapter or a part thereof, you must distribute your contributions under the same licence as the original. This publication is also available at the UNESCO Open Access Repository: https://unesdoc.unesco.org/

The designations employed and the presentation of material throughout this publication do not imply the expression of any opinion whatsoever on the part of UNESCO concerning the legal status of any country, territory, city or area or of its authorities, or the delimitation of its frontiers or boundaries.

The authors are responsible for the choice and the presentation of the facts contained in this chapter and for the opinions expressed therein, which are not necessarily those of UNESCO and do not commit the Organization.

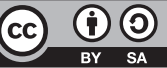

